\title{
0825 AGE AND THE SOCIAL MEANING OF WEARING A BICYCLE HELMET AMONG SWEDISH TEENAGERS
}

M Eliasson*, K Johansson, L Laflamme Correspondence: Department of Public Health Sciences, Division of Applied Public Health, Karolinska Institutet, Box 17070, Stockholm SE-104 62, Sweden

\subsection{6/ip.2010.029215.825}

The aim of this study is to understand the social meaning of wearing a bicycle helmet among teenagers, in relation to their constructions of age. In Sweden, using a helmet when bicycling was made compulsory by law for children under the age of 15 in 2005. Despite this, only 20 percent of $13-15$ year-olds use a helmet. However, helmet use is not only a question of protecting oneself from injury, but also conveys social meaning about what kind of a person the wearer is. The study draws on ten focus group discussions (including 50 participants in total) with 15- to 16-year-old Swedish girls and boys. The material was transcribed and analysed using discourse analysis. According to the girls and boys, the most important barriers to helmet use related to their social identity. Central was the understanding of helmets as uncool and childish, which in turn was tied to bicycling not being seen as dangerous when that skill has been mastered. Ceasing to use helmets when becoming a teenager was described as inevitable and part of growing up. Safety discourses framing helmets as necessary protection against injury were largely overridden 


\section{IP Safety 2010 abstracts}

by the age- and identity-related discourses. Among teenagers, not using a bicycle helmet can contribute to the production of a positive social identity as older, fearless, and independent from adults. Using a helmet is associated with a social cost, which in many cases carries more weight than the possible risk of injury. 